\title{
Effects of random damages on dynamic behavior of metallic sandwich panel with truss core
}

\author{
Lingling Lu a, b, Hongwei Song a, b, *, Chenguang Huang a, b \\ a Key Laboratory for Mechanics in Fluid Solid Coupling Systems, Institute of Mechanics, Chinese Academy of Science, Beijing, 100190, China \\ b School of Engineering Science, University of Chinese Academy of Sciences, Beijing, 100049, China
}

\section{A R T I C L E I N F O}

\section{Article history:}

Received 13 June 2016

Received in revised form

8 September 2016

Accepted 18 October 2016

Available online 24 October 2016

\section{Keywords:}

Sandwich panel with truss core

Random damages

Natural frequency

Mode shape

Boundary condition

\begin{abstract}
A B S T R A C T
Random damages in the core or face/core interface often appears during fabrication or application of metallic sandwich panels with truss core, and may significantly affect the dynamic behavior of the sandwich panel. Two types of evaluation parameters, i.e., global parameters and local parameters, are used to evaluate the effect of random damages. A finite element model in conjunction with stochastic number program that can automatically specify random damages of various extents is developed. Experiments were conducted to verify the proposed analytic model and technique. Three factors affecting dynamic properties of the damaged sandwich are considered, including damage extent, boundary condition and damage zone. Results show that variations of structural dynamic property are in proportional to the damage extent and the concentration degree of random damages, and increases as the constraint of boundary condition is enhanced. Effects of random damages on both natural frequencies and mode shapes are usually in accordance. Damages in the zone covering structural local vibration modes or maximal vibration amplitude would have greater influences on natural frequencies and mode shapes than damages in other zones.
\end{abstract}

() 2016 Elsevier Ltd. All rights reserved.

\section{Introduction}

Sandwich panels with cellular cores have many superior properties, such as light weight, high specific bending stiffness, good acoustical isolation and thermal insulation [1-4]. The light-weight cellular core can be in the form of stochastic foam, periodic honeycomb, corrugated sheet and lattice truss, etc. [5-7]. As a class of newly developed multifunctional structures, sandwich panels with truss cores (SPTCs) [8-10] are considered as most promising thermal protection structures and have been increasingly applied in aircrafts and aerospace engineering. However, damages may occur in the panel due to complicated service environment, such as impact force, aerodynamic force, intense local heating, etc, and damages may include breakage of truss member, burn-through of face sheets, buckling of the panel, etc. [11,12]. Besides, during the manufacturing process, some defects may also arise, for example

\footnotetext{
* Corresponding author. Key Laboratory for Mechanics in Fluid Solid Coupling Systems, Institute of Mechanics, Chinese Academy of Science, Beijing, 100190, China; School of Engineering Science, University of Chinese Academy of Sciences, Beijing, 100049, China.
}

E-mail address: songhw@imech.ac.cn (H. Song). unbounded truss nodes to the face sheet, truss member fracturing and bending. Mechanical properties of the SPTCs, such as structural stiffness and strength, critical buckling temperature, natural frequencies and vibration modes, would be altered by damages and defects, and the risk of structural failure is thereafter increased. The variation of mechanical properties due to damages should be investigated to supply references for the early detection of damages in SPTCs, which is extremely important for structural maintenance, risk evaluation and residual life assessment.

As Russell and Hilary claimed, the SPTCs' sensitivity to imperfections on stiffness and load capacity should be examined and quantified before they can be implemented as structural components in the field [13]. They reported the retention of SPTCs' stiffness and load capacity in the presence of imperfections. Results show that imperfections (unbound nodes between the core and face sheets) could cause rapid degradation of core shear properties. In the early work, influence of imperfection on the mechanical performance of the truss material is also studied by Wadley et al. [10] and Evans et al. [14].

The effect of damages and defects on the dynamic behavior of sandwich structures is also investigated. Hu and Hwu [15] examined the effect of delamination on free vibration of composite 
sandwich, and it is shown that the existence of delamination will lower the natural frequencies. Kim and Hwang [16] investigated the effect of debonding extent on the flexural stiffness and natural frequency of honeycomb sandwich beam, which decreases as the debonding emerges or the extent of debonding increases. Sokolinsky et al. [17] used the higher-order theory approach to analyze the free vibration of sandwich beam with a locally damaged core. Results show that a small local damage would cause significant changes in natural frequencies and vibration modes. Burlayenko and Sadowski [18] studied effects of debonding size, location and type on vibration behaviors of composite sandwich plate with different boundary conditions, and the study is useful for the nondestructive damage detection of partially debonded sandwich plates. Baba and Thoppul [19] investigated the effect of face/core debonding on the vibration behavior of a composite sandwich beam. Buket and Srinivasa [20] studied the influence of curvature and face/core debonding on the vibration behavior of composite sandwich beams. It is found that natural frequencies decrease with the presence of debonding. However, the face/core debonding causes the increasing of damping loss factor. Recently, Lou et al. [21] studied the influence of damages on vibration behavior of composite SPTCs through numerical simulation. Based on the effect of damages on structural mechanical property, some damage indexes that are sensitive to structural damages, are proposed for damage identification of sandwich structures [22-29].

In previous works, damages and defects are specially given in a certain location. However, due to the complexity of service environments, some damages in a SPTC may be randomly distributed, for example when an unexpected impact force hitting the SPTC structure. Meanwhile, due to the immaturity of fabrication technology, random defects may arise during the manufacturing process. The effect of random damages and defects in the case of different boundary conditions, different extents on SPTCs' mechanical properties is complicated. In 2001, Wallach and Gibson [30] studied the effect of randomly distributed defects of a 3D truss material on Young's modulus and compressive strength numerically. It is found that the modulus and strength decrease linearly with the fraction of members removed. However, up to now, the effect of random damages on the dynamic behavior of SPTCs has not been systematically investigated.

In the present study, the effect of random damages on metallic SPTCs' dynamic behavior is investigated. Influences of damage extent, boundary condition and damage zone are considered. In Section 2, evaluation parameters are defined to analyze the effect of random damages on SPTCs' dynamic properties. In Section 3, a 3D finite element model combined with a MATLAB program, which can automatically specify random damages of various extents in a given region, is developed. In Section 4, experiments of healthy and damaged pyramidal SPTCs are conducted to verify the proposed analytical model and technique. In Section 5, effects of random damages on structural dynamic property are analyzed, and influences of the damage extent and boundary condition are discussed. Besides, several zones are classified, and influences of random damages appeared in different zones under different boundary conditions are compared and discussed. Finally, some conclusions are obtained in Section 6.

\section{Evaluation parameters}

To evaluate the influence of random damages on SPTCs' dynamic property, two types of parameters are defined, i.e., global evaluation parameters and local evaluation parameters. Typically natural frequency can be taken as a global parameter, and the difference of natural frequency between the damaged SPTC and healthy SPTC reflects the variation of global vibration properties. Mode shape contains vibration information of every local points, therefore can be utilized to describe the local vibration properties. Based on mode shapes, $\operatorname{COMAC}\left(\mathrm{x}_{\mathrm{j}}\right)$ is defined to evaluate the relationship of mode values of point $x_{j}$ before and after damage. Therefore evaluation parameters based on $\operatorname{COMAC}\left(\mathrm{x}_{\mathrm{j}}\right)$ can reflect the influence of damages on structural local vibration properties.

\subsection{Global evaluation parameters}

To evaluate the effect of random damages on SPTCs' global dynamic property, the differential of the $i$-th order natural frequency $\Delta f_{i}$ is defined

$\Delta f_{i}=\frac{\left|f_{i}^{D}-f_{i}^{I}\right|}{f_{i}^{I}}$

where $f_{i}^{D}$ and $f_{i}^{d}$ are the $i$-th order natural frequencies of the damaged and intact specimens respectively.

To evaluate and compare the effect of random damages in the case of different extents, the average differential value of natural frequency $\delta_{i}$ is also defined as

$\delta_{i}=\frac{\sum_{t=1}^{N} \Delta f_{i}^{t}}{N}$

where $\Delta f_{i}^{t}$ is the $i$-th order natural frequency differential of the $t$-th random damage case. $N$ is the total number of random damage cases being numerically modeled in the same damage extent. By analyzing results of $\Delta f_{i}$ and $\delta_{i}$, the effect of random damages on structural global properties could be obtained.

\subsection{Local evaluation parameters}

Coordinate modal assurance criterion (COMAC) [31] is an extension of modal assurance criterion (MAC) [32] and is calculated as

$\operatorname{COSMAC}\left(x_{i}\right)=\frac{\left[\sum_{k}\left|\psi_{k}\left(x_{j}\right) \phi_{k}\left(x_{j}\right)\right|\right]^{2}}{\left[\sum_{k}\left|\psi_{k}\left(x_{j}\right)\right|^{2}\right]\left[\sum_{k}\left|\phi_{k}\left(x_{j}\right)\right|^{2}\right]}$

where $\psi_{k}\left(x_{j}\right)$ and $\varphi_{k}\left(x_{j}\right)$ are the $k$-th mode value of point $x_{j}$ of the damaged model and intact model respectively. COMAC attempts to identify which measurement positions (or DOFs) contribute negatively to a low value of MAC. Because mode values of points in the damaged zone would change, the coordinate with a lowest COMAC is likely to be damaged. Therefore, two local evaluation parameters, i.e., average COMAC and minimum COMAC are defined as

$A v C O=\left(\sum_{x_{j}} \operatorname{COMAC}\left(x_{j}\right)\right) / T$

$\operatorname{MinCO}=\min (\operatorname{COSMAC})$

where $T$ is total number of points.

The average COMAC could be used to evaluate the average effect of random damage on structural mode shapes, and the minimum COMAC could reflect the influence of random damages on the structural local mode shapes. Both two parameters could evaluate the influence of damages on structural mode shapes. The smaller two parameters are, the larger influences of random damages on 
structural mode shapes are.

\section{Numerical model and random damage process}

Fig. 1 shows the schematic of the model for pyramidal SPTC being simulated. Fig. 1 (a) gives the unit cell of pyramidal truss, the cross section of the truss bar is square with the width of $t_{c}=1 \mathrm{~mm}$, and the dimension of unit cell is $\mathrm{h}_{\mathrm{c}}=8 \mathrm{~mm}$ in height, and $\mathrm{L}_{1}=\mathrm{L}_{2}=11.3 \mathrm{~mm}$ in width. The SPTC model is as shown in Fig. 1 (b), which is made of stainless steel with Young's modulus of $200 \mathrm{GPa}$, Poisson ratio of 0.3 , and mass density of $7800 \mathrm{~kg} / \mathrm{m}^{3}$. The dimension of the face sheet is $250 \times 250 \times 1 \mathrm{~mm}$. There are 20 unit cells of pyramidal truss along the $x$ and $y$ direction of the panel respectively.

A finite element model is developed by the commercial software ANSYS to analyze mode shapes of pyramidal SPTC with and without local damages. 'Beam189' and 'Shell181' are selected for truss bars and the face sheets in the numerical model respectively. Nodes of truss bars and face sheet at the same location are coupled together to obtain the connection relationship between truss bars and face sheet. The finite element model is combined with a MATLAB program to automatically specify random damages of various extents in a given region. In the MATLAB program, the $x$ coordinate and $y$ coordinate of the confluence node of a damage cell are set as variables. Based on random number, coordinates of damaged cells are randomly selected for a certain damage extent. By setting the range of coordinate variables, damaged cells can be randomly located in a given zone. Cell missing damage is considered in the present study. Once identified as damaged cell, bars of the missing cell are deleted. The finite element model is then meshed and modal analysis of the damaged SPTC is conducted. Then dynamic performance of the damaged SPTC, including natural frequencies and mode shapes, can be obtained. Based on the obtained mode information, the four evaluation parameters could be calculated and the effect of the defined random damages on structural dynamic properties can be evaluated.

Random cell missing is the main damage type considered in the present study. The damage extent $\eta$ is expressed as

$\eta=\frac{N_{\text {mis } \sin g}}{N_{\text {Total }}}$

where $N_{\text {missing }}$ is the number of missing cells, and $N_{\text {Total }}$ is the total cell number of the intact model. In the work, $N_{\text {Total }}$ is 400 , and $N_{\text {missing }}$ is set from 4 to 40 , therefore $\eta$ is varied from 0.01 to 0.1 . $N_{\text {missing }}$ damages are randomly distributed throughout the specimen or in a given zone. In the work, the total number of random damage cases $N$ is set as 15, i.e., at a given damage extent 15 numerical cases of randomly distributed damages in total are simulated.

\section{Experimental verification}

To verify the reliability of the proposed analytic technique and the numerical model, vibration experiments of damaged and healthy SPTC specimens are conducted. Comparisons between experimental and numerical results in the case of the same damage extent are also carried out.

\subsection{Experimental setup}

The experimental setup is as shown in Fig. 2. Healthy metallic pyramidal SPTC specimen and specimens with pre-fabricated damages are excited by a shaker (JZK-50). Two edges of specimens are clamped. The excitation signal is generated by the control system of a laser Doppler vibrometer (Polytec, PSV-400) and amplified by a power amplifier (YE5874A) before input to the shaker. The frequency bandwidth of the excitation signal was set in the range of $0-2 \mathrm{kHz}$ with the resolution of $1 \mathrm{~Hz}$.

The structural vibration response is measured by the laser Doppler vibrometer. The measuring points are focused on the front surface of the face sheet, and the excitation is on the other side of the face sheet. The distribution of measuring points of a specimen is as shown in Fig. 3. The obtained excitation and structural response signal are used to calculate the frequency response function (FRF) to get the structural modal information, including natural frequencies and modes. In order to obtain good quality of modal information, the FRF for each scanning point was averaged three times.

\subsection{Fabrication of specimens}

Folding of a perforated metal sheet provides a simple way to make a lattice truss core. In the present work, the metal pyramidal

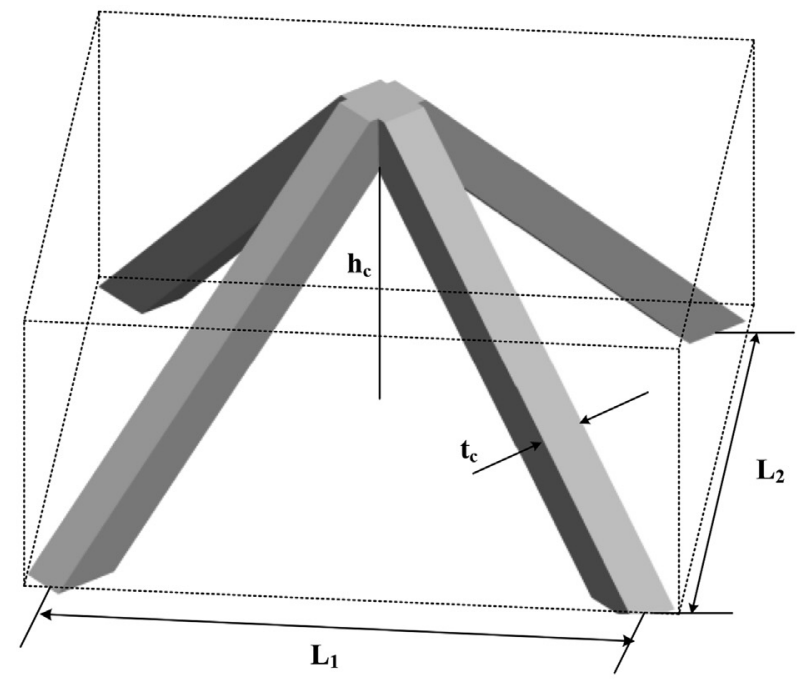

(a)

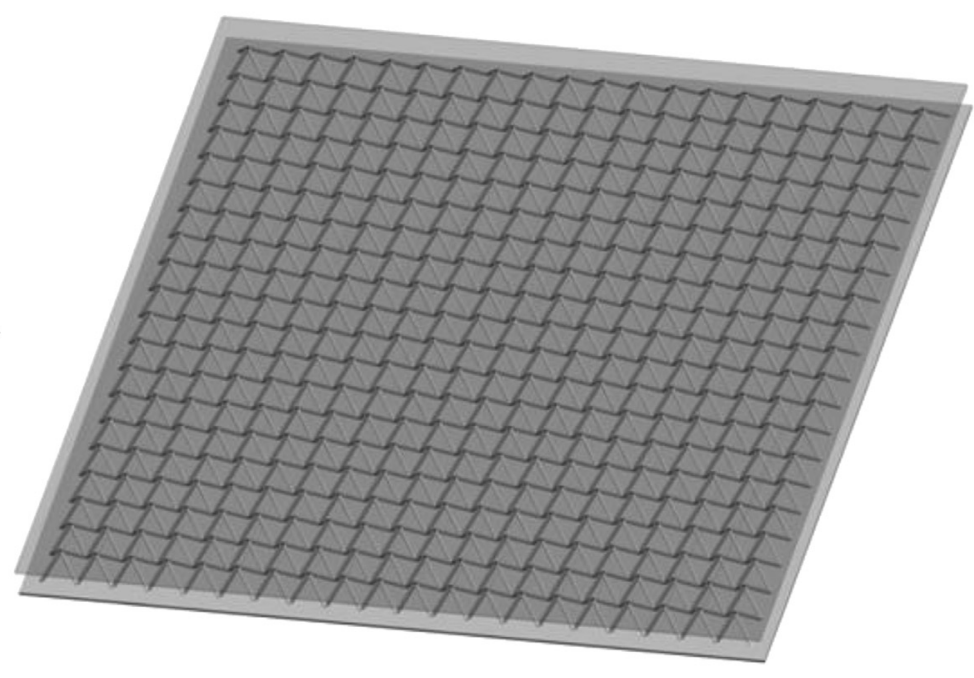

(b)

Fig. 1. Numerical model of pyramidal SPTC. (a) Unit cell of pyramidal truss. (b) The sandwich panel with pyramidal truss core. 


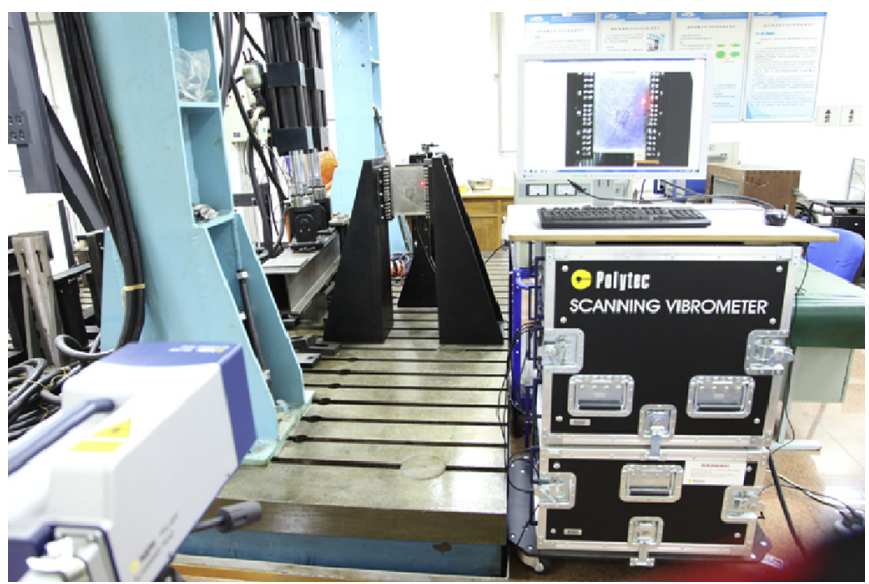

Fig. 2. Experimental setup.

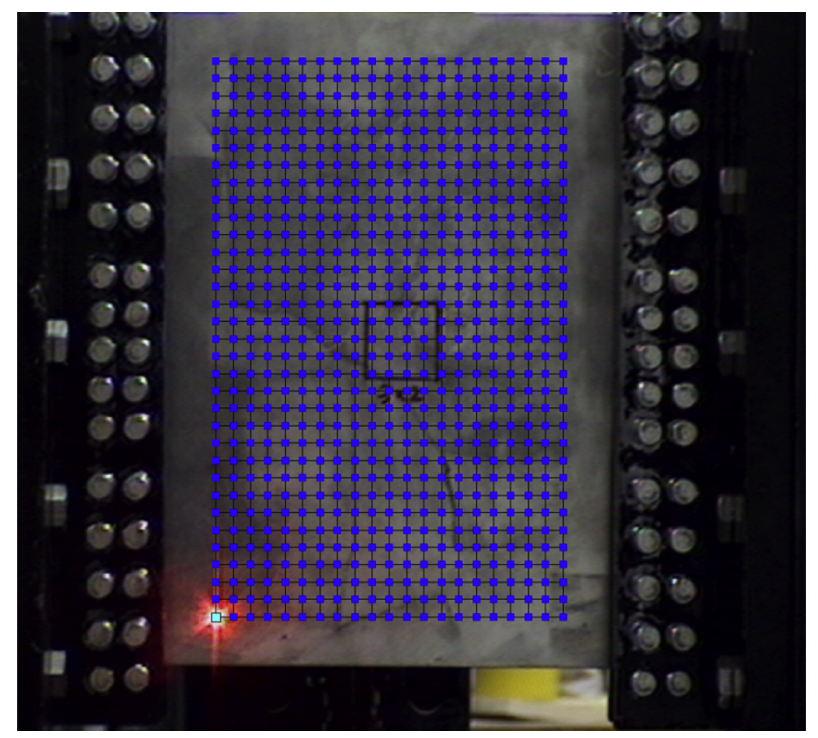

Fig. 3. Distribution of measuring points.

truss cores with a relative density $\rho$ of about $3 \%$ are fabricated from $0.7 \mathrm{~mm}$ thick stainless steel wire mesh. The stainless steel wire mesh was folded into pyramidal truss cores by using a punch-anddie pair of $60^{\circ}$ angle. The sketch of the punching operation to fold the perforated sheet into pyramidal truss cores is as shown in Fig. 4(a). The punch-and-die pair is designed with a $3 \mathrm{~mm}$ terrace to obtain flat areas at nodal regions, in order to avoid node fracture and enlarge the joint area between truss cores and face sheets. Then brazing technique was employed to join the truss core and face sheets, obtaining a complete SPTC specimen. The thicknesses of face sheets and truss core are $0.9 \mathrm{~mm}$ and $7 \mathrm{~mm}$ respectively.

In the study, cell missing damages are used to simulate structural damage. The truss core cells of the damage location are cut out before brazing. Specimens with single damage location are used and three damage extents are considered, named SD2 $\times 3$, SD3 $\times 4$ and SD $4 \times 5$, where $x \times y$ represents the damage extent, $x$ and $\mathrm{y}$ are the numbers of missing cells in $\mathrm{x}$ and $\mathrm{y}$ direction respectively. Schematic diagrams indicating the damage location of three damaged specimens are shown in Fig. 4 (b). The defined damages are in the center of specimens. The healthy specimen is named SD0.

\subsection{Experimental results and comparison with simulation}

To validate the proposed analytical method, numerical models of the same dimensions as real specimens are also built, where $\mathrm{h}_{\mathrm{c}}=7 \mathrm{~mm}, \mathrm{t}_{\mathrm{c}}=1 \mathrm{~mm}, \mathrm{~L}_{1}=15.9 \mathrm{~mm}, \mathrm{~L}_{2}=9.18 \mathrm{~mm}$. There are 14 and 24 unit cells of pyramidal truss along the $\mathrm{x}$ and $\mathrm{y}$ direction of the panel respectively.

Different from real specimen, whose damaged zone is prefabricated and certain, numerical model can simulate various cases of randomly distributed damages that have the same damage extent as real specimen. In simulations, the number of random damage cases $N$ is set to 50 . Sufficient number of numerical cases is helpful to locate the boundary performance (upper limit and lower limit) of damaged SPTC of a certain damage extent. After calculation, the $\mathrm{f}_{1}^{\mathrm{D}} / \mathrm{f}_{1}^{\mathrm{f}}$ results of experiments and simulations are shown in Fig. 5.

According to the results in Fig. 5, it is observed that the trend of $\mathrm{f}_{1}^{\mathrm{D}} / \mathrm{f}_{1}^{\mathrm{I}}$ of simulation is in accordance with experiment as the damage extent increases, although there are errors between the experiments and simulations and the error increases as the damage extent increases. Because the numerical model is perfect one, whereas experimental specimens always have flaws during the fabrication process. Meanwhile, the discreteness of the $\mathrm{f}_{1}^{\mathrm{D}} / \mathrm{f}_{1}^{\mathrm{l}}$ results would increase as the damage extent increases, as the simulation limit curves shown in Fig. 5. Based on the experimental and numerical results, it demonstrates that the simulation model is acceptable and the proposed analytic technique can reflect the basic tendency.

\section{Simulation results and discussions}

\subsection{Outline of key factors}

Many factors could influence the effects of random damages on global and local vibration properties of SPTCs, such as damage extent, boundary condition and damage distribution. In this section, effects of random damages on structural dynamic properties are analyzed and influences of the above-mentioned three factors are also discussed. Ten groups of damage extents are considered, with $\eta$ setting from 0.01 to 0.1 . Three different boundary conditions are applied, including one side clamped and three sides free (CFFF), two sides clamped and two sides free (CCFF) and fully champed (CCCC). Because the effect of random damages appeared in different zones of the specimen is diverse, specimens in the case of different boundary conditions are divided into several zones. Effects of damages in different zones on the vibration property of SPTCs are compared and discussed.

\subsection{The effect of damage extent and boundary condition}

The effect of damage extent and boundary condition in the cases of CFFF, CCFF and CCCC is discussed in the section. $\Delta f_{i}$ results of the first six order modes are shown in Fig. 6.

Variations of dynamic behaviors would increase as the damage extent increases, and the fitting curves in Fig. 6 could demonstrate this tendency. At the same damage extent $\eta$, it is seen from Fig. 6 (a) that $\Delta f_{1}$ values of the 15 random damage cases are diverse a lot. For example, when $\eta$ is 0.1 , the smallest $\Delta f_{1}$ in the case of CCFF is about $2.3 \%$ and the biggest $\Delta f_{1}$ is nearly $5 \%$. Similar phenomenon could also be found from Fig. 6 (b) (f). It gives clues that the distribution (including damage locations and the concentration degree of damages) of random damages in the case of the same damage extent $\eta$ influences the effect of random damages on SPTC's vibration property greatly. When results of numerical cases in a specific boundary condition are being fitted, the obvious tendency 


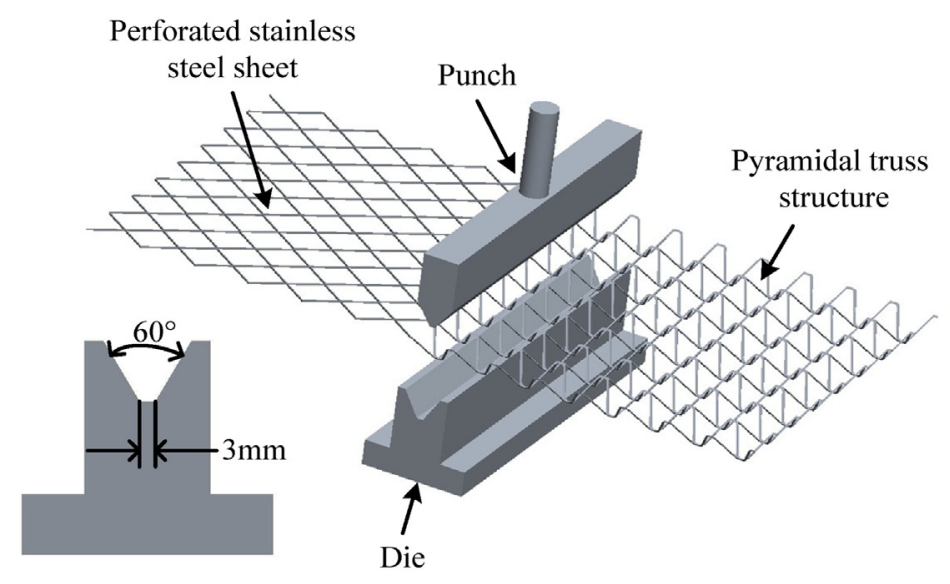

(a)

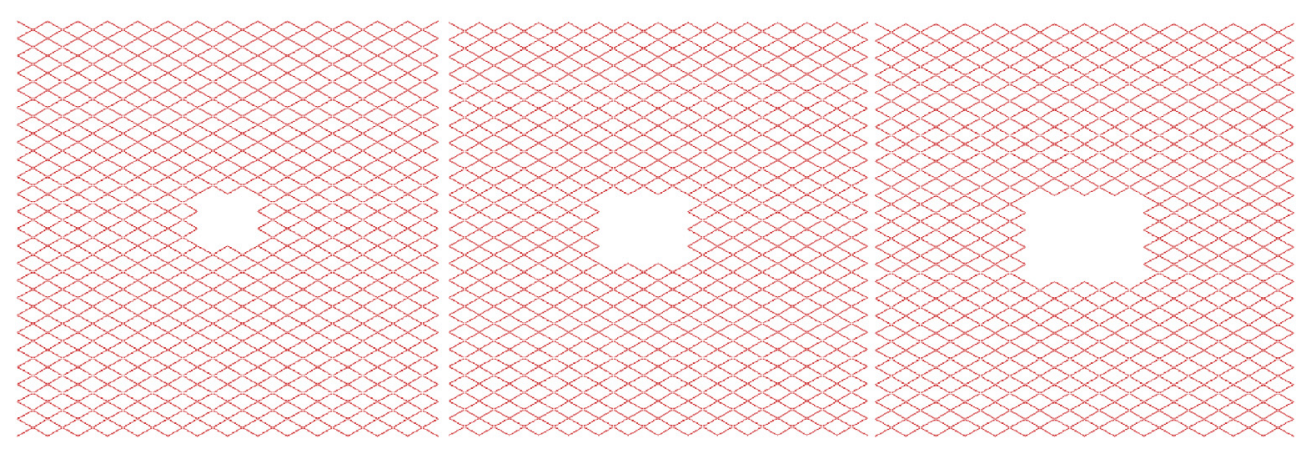

(b)

Fig. 4. Specimen preparation. (a) Punching operation for manufacturing pyramidal truss cores. (b) Schematic diagrams of damage location of SD2 $\times 3$, SD3 $\times 4$, SD $4 \times 5$.

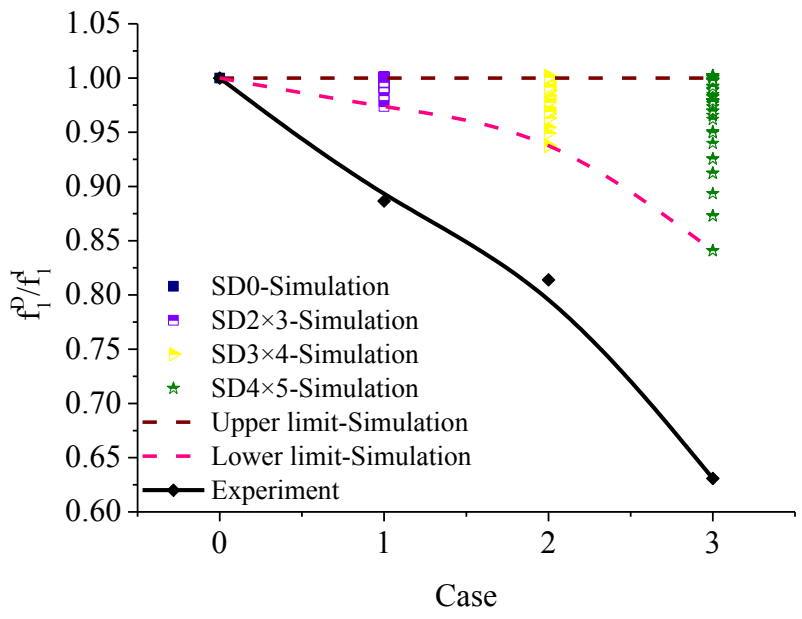

Fig. 5. Numerical and experimental results.

can be tracked.

Normally, higher order modes are more sensitive to damage than lower order modes, due to the complicated vibration mode shape which is sensitive to damages. For example, for the SPTC specimen in the case of CFFF, 1 st mode is the 1 st bending vibration mode and 3rd mode is the 2nd bending vibration mode (Fig. 8 (a) and (c)), 2nd mode is the 1 st torsion vibration mode and 4 th mode is the 2 nd torsion vibration mode (Fig. 8 (b) and (d)). Fig. 6 (a) to (d) show that maximal variations of $\Delta f_{i}$ of the 2 nd bending and torsion mode shapes (3rd mode and 4th mode) caused by random damages are larger than the 1st mode shapes (1st mode and 2nd mode) in the case of the same damage extent.

From Fig. 6 (a) to (f), it is also observed that the variation of $\Delta f_{i}$ value in the case of the same damage extent increases as the constraint of the boundary condition increases. The global vibration modes would become complicated and more detailed local vibration modes would appear as the boundary condition becomes strict. The complicated global and local vibration modes are more sensitive to damages. Therefore, as the boundary condition becomes strict, normally variations of structural vibration properties increase in condition of the same damage extent and the same order mode.

\subsection{The effect of random damages in different zones}

In each case of the three boundary conditions, several zones are classified and effects of random damages appeared in different zones on structural dynamic behavior are studied. The identification of damage sensitive zones in the case of different boundary conditions is instructive for structural damage identification.

\subsubsection{Boundary condition CFFF}

The SPTC specimen in the case of CFFF is divided into three zones as shown in Fig. 7, and the first six modes are shown in Fig. 8. $\Delta f_{i}, A v C O$ and MinCO results in the cases of random damages located in zone 1, 2 and 3 are shown in Fig. 9 and Fig. 10 respectively.

According to the fitting curves in Figs. 9 and 10, it is seen that the 


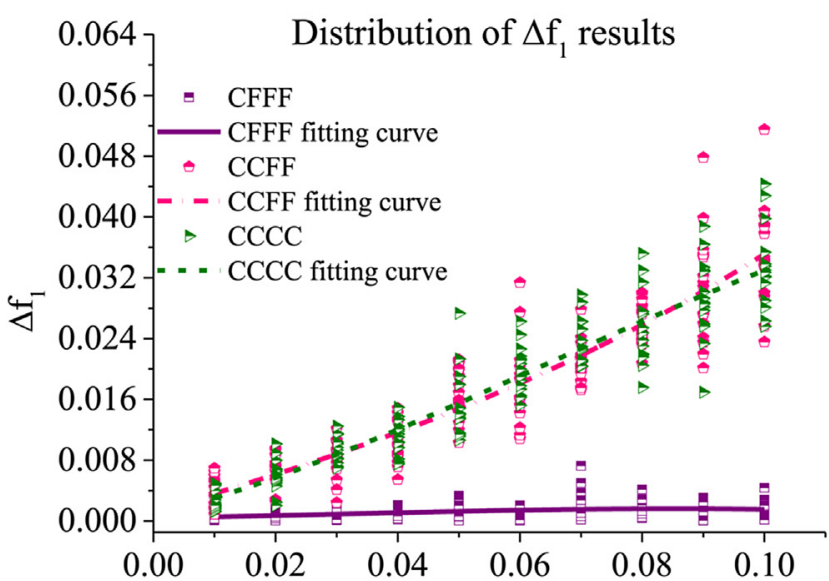

$\eta$

(a)

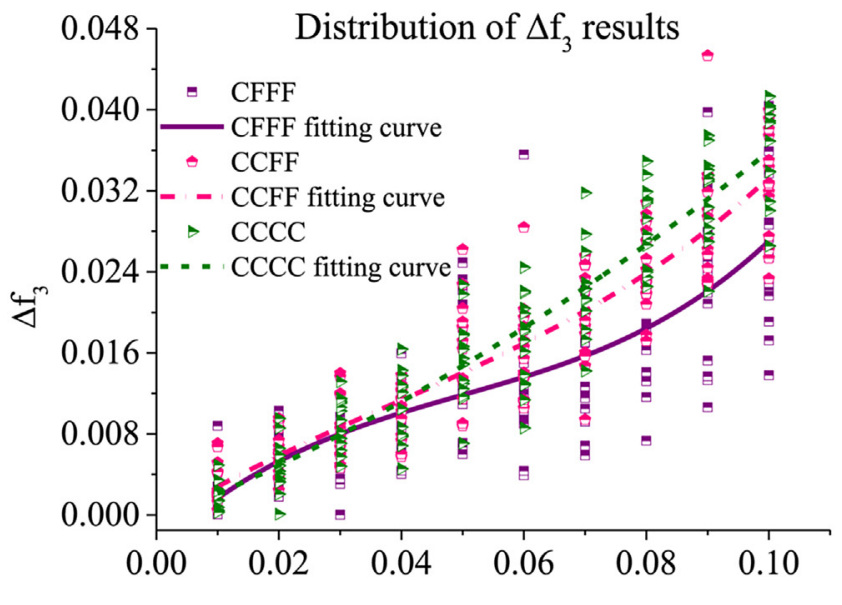

(c)

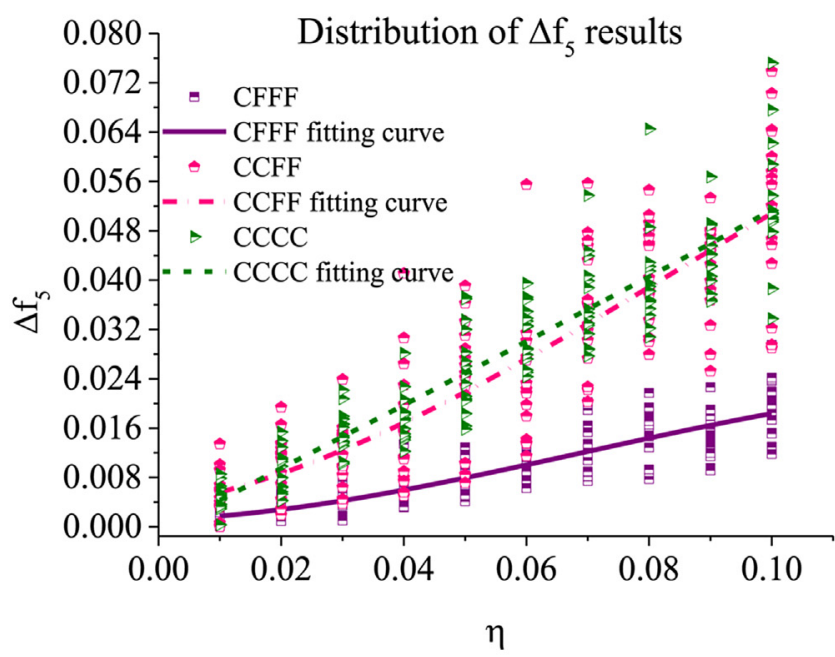

(e)

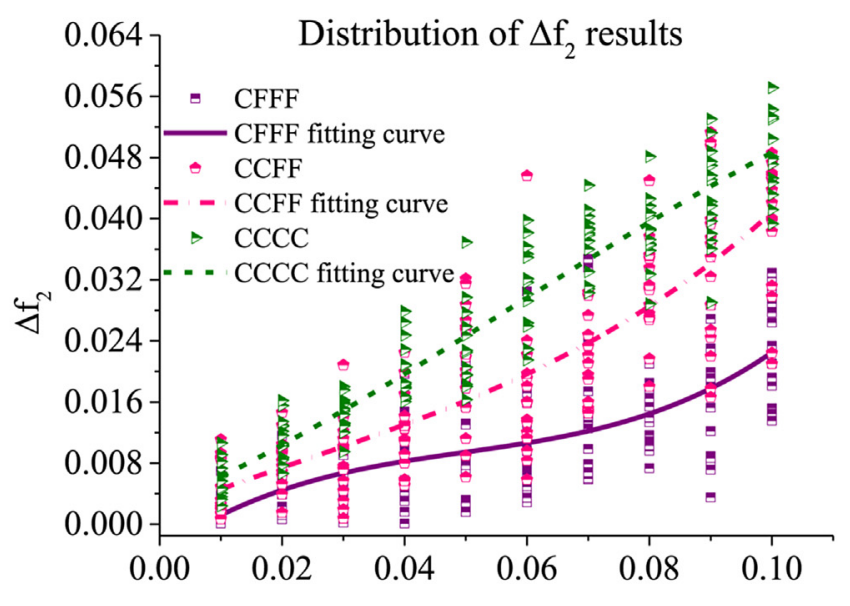

$\eta$

(b)

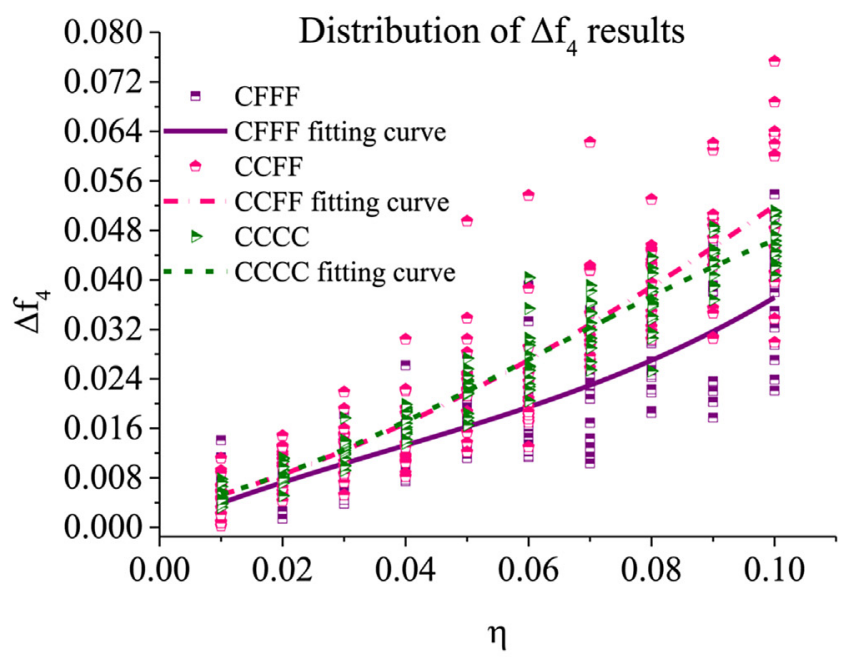

(d)

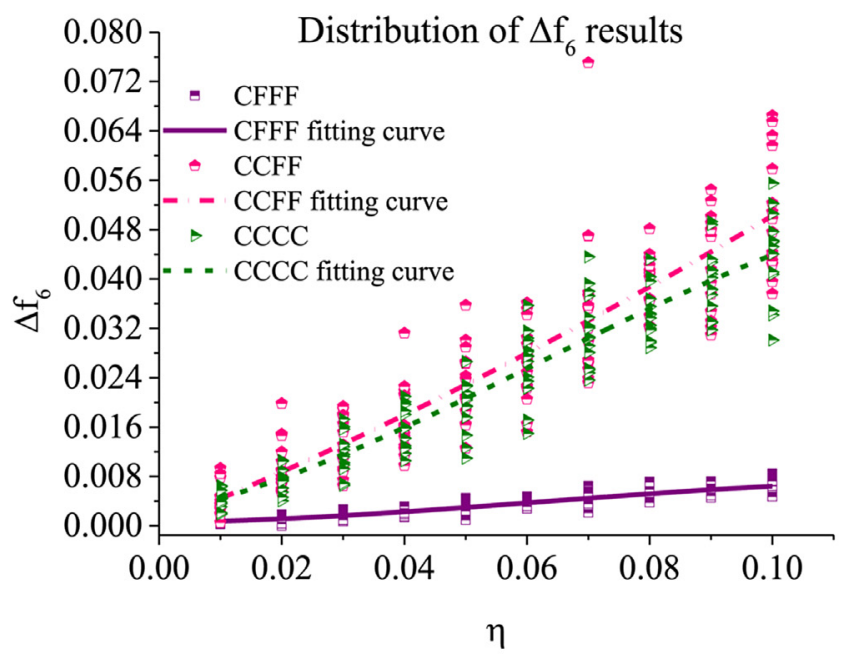

(f)

Fig. 6. $\Delta f_{i}$ results of different boundary conditions. (a) 1 st mode. (b) 2 nd mode. (c) 3 rd mode. (d) 4 th mode. (e) 5 th mode. (f) 6 th mode. 


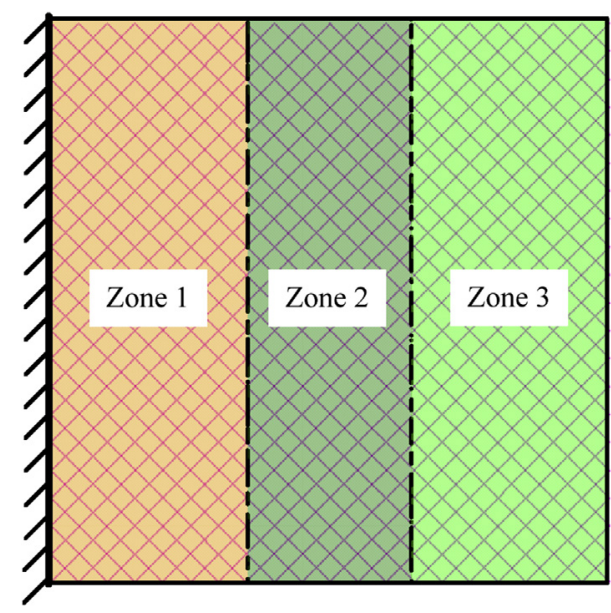

Fig. 7. Three zones of the specimen in the case of CFFF.

statistic results of the evaluation parameters are regular, although the discreteness of the three parameters' results are very large. Meanwhile, it is also observed that the discreteness of the global parameter $\Delta f_{i}$ is smaller than those of the local parameters $A v C O$ and MinCO. Since the local parameters are more sensitive to damages than the global parameters. Based on the statistic results of both global and local evaluation parameters, some conclusions could be obtained.

From Fig. 9 (a) to (d), it is seen that variations of 1st, 2nd, 3rd and 4th natural frequencies caused by damages in zone 1 are much larger than the other two regions, and it is also found that $\Delta f_{5}$ and $\Delta f_{6}$ caused by damages in zone 3 are higher than zone 1 and zone 2 . It indicates that the effect of damages on structural dynamic properties is influenced by both the distribution of random damages and mode shapes of SPTC.

According to the AvCO and MinCO results shown in Fig. 10, it is seen that variations of mode shapes caused by random damages in zone 1 and 3 are larger than those caused by damages in zone 2 . The same trends of natural frequencies can be obtained as shown in Fig. 9. It is found that variations of mode shapes caused by damages are usually in accordance with variations of natural frequencies.

According to the fitting curves in Figs. 9 and 10, it is also found that the sensitivities of different modes to random damages in different zones are diverse a lot, which are determined by both damage distribution and vibration mode.

\subsubsection{Boundary condition CCFF}

Fig. 11 shows the classification of four zones for the CCFF specimen, and the first six modes are shown in Fig. 12. It is found from Fig. 12 that the 4 th, 5 th and 6 th modes are the higher order mode of the 1st, 2nd and 3rd modes respectively. Evaluation parameters for damages in different zones are shown in Fig. 13 and Fig. 14.

Compared with damages in zone 1, 3 and 4, effects of damages in zone 2 on different modes are of great difference. Fig. 13 (b) shows that variations of the 4 th, 5th and 6th order natural frequencies caused by damages in zone 2 are much larger than those of the $1 \mathrm{st}$, 2nd and 3rd order natural frequencies. On the one hand, the 4th, 5 th and 6th modes are higher order vibration modes of the 1st, 2nd and 3rd order modes respectively, and are more complicated than 1 st, 2 nd and 3rd modes. On the other hand, the 4th, 5th and 6th vibration modes deform in symmetrical patterns, and zone 2 covers the central axis region around which the vibration modes deform, as the red rectangular frame shown in Fig. 12. When damages are in the zone 2 , the stiffness decrease in zone 2 would have great influences on 4th, 5th and 6th modes.

However, Fig. 13 (d) shows that variations of 1st, 3rd, 4th and 6th modes are much larger than those of 2nd and 5th modes when damages are in zone 4. In Fig. 12 (b) and (e), the red dotted lines are the symmetry axis of 2 nd and 5 th modes. Since the clamped boundary condition restricts the vibration of regions near both sides, effects of random damages in zone 4 on the two vibration modes are also suppressed.

From Fig. 12 (a) to (f), it is observed that zone 3 covers the local vibration modes of 2 nd, 3rd, 5th and 6th mode shapes and it also covers the maximal vibration amplitude zones of the first six modes. Therefore, variations of the mode shapes caused by

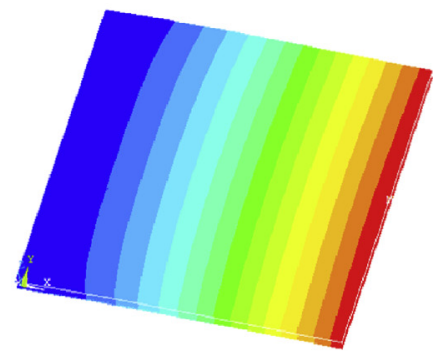

(a)

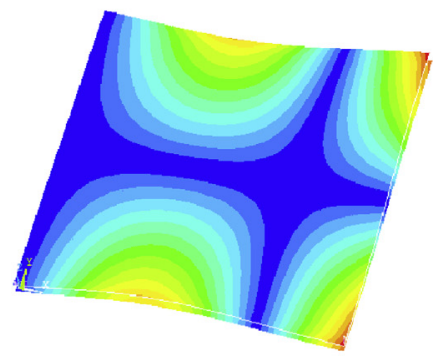

(d)

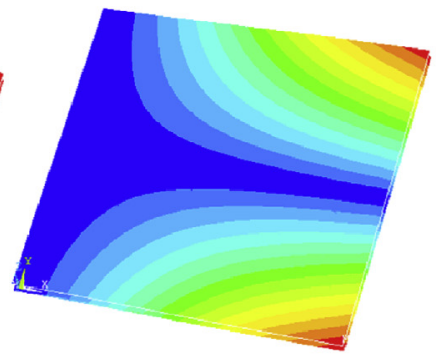

(b)

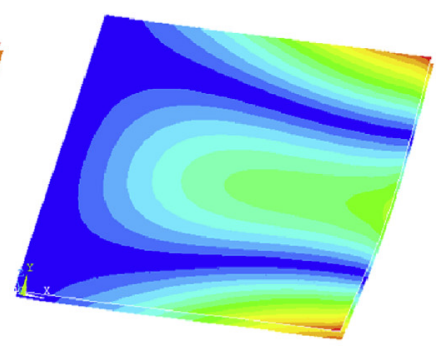

(e)

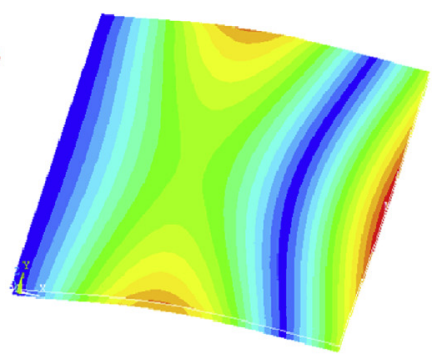

(c)

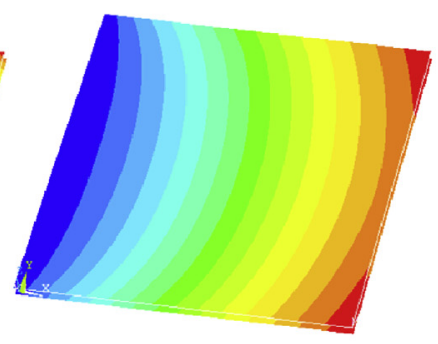

(f)

Fig. 8. First six modes in the case of CFFF. (a) 1st mode. (b) 2nd mode. (c) 3rd mode. (d) 4th mode. (e) 5th mode. (f) 6 th mode. 


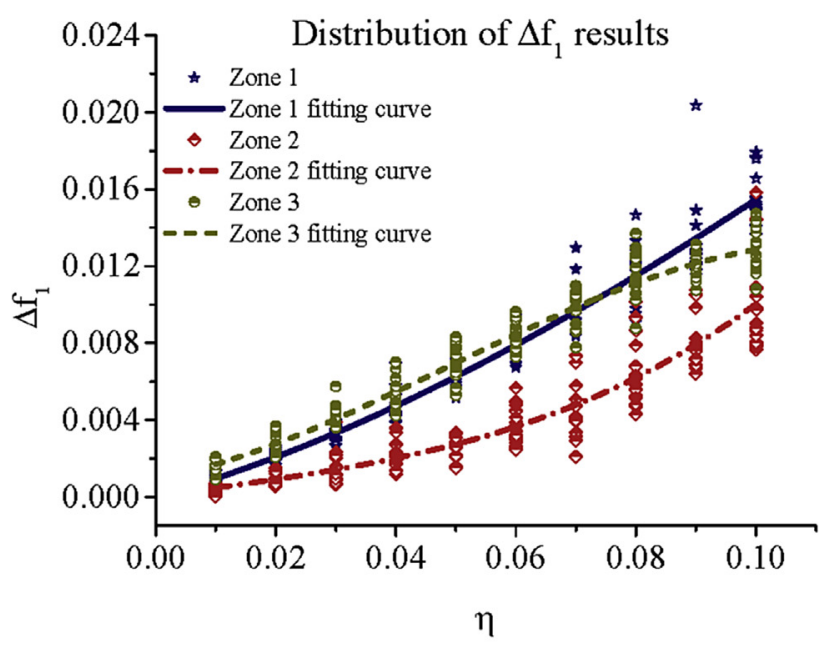

(a)

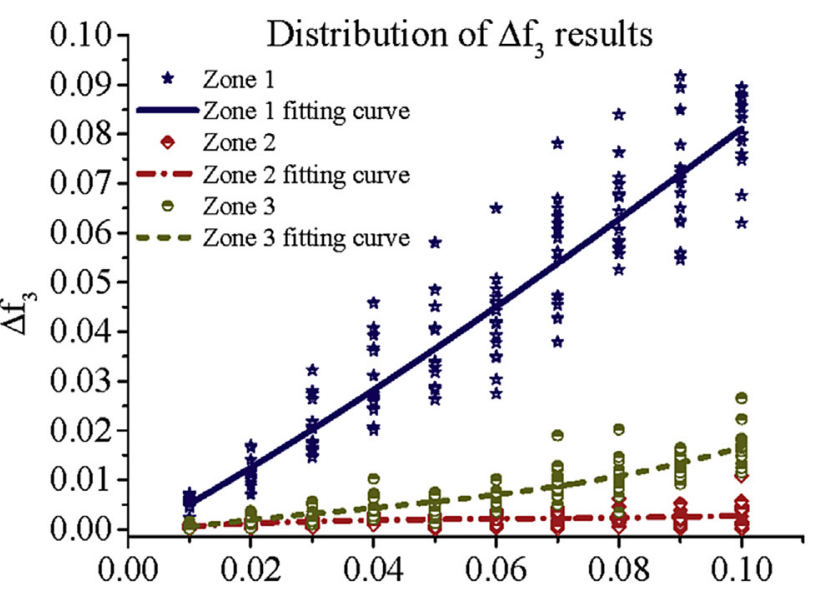

$\eta$

(c)

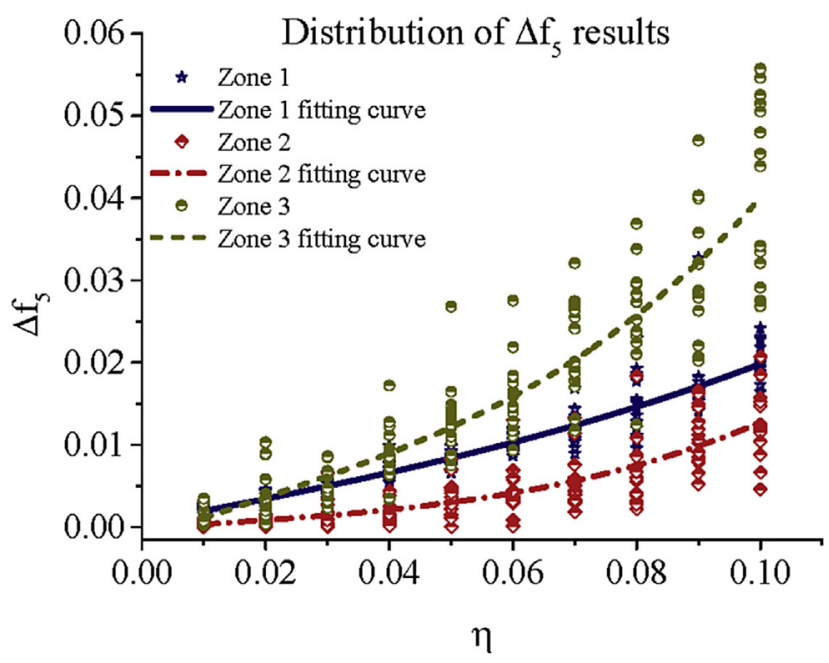

(e)

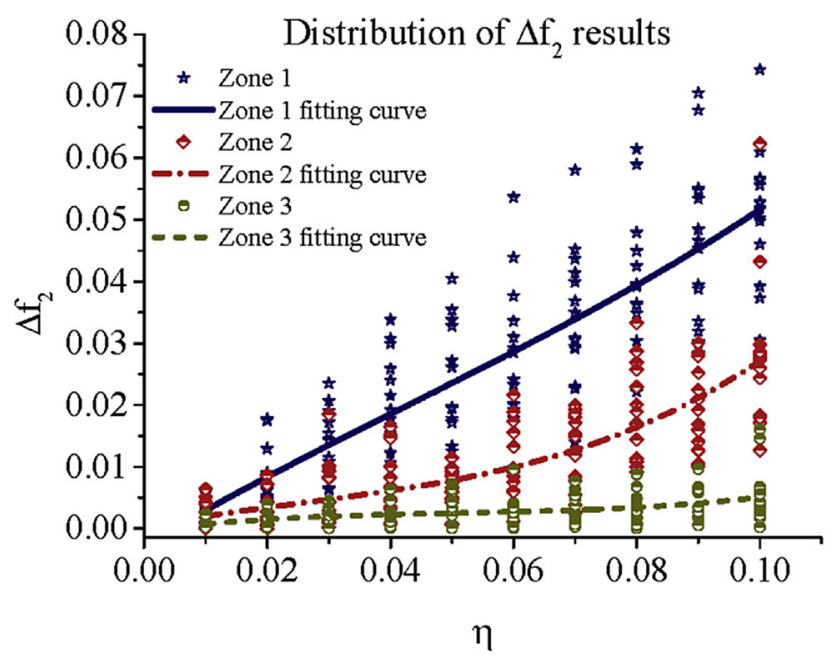

(b)

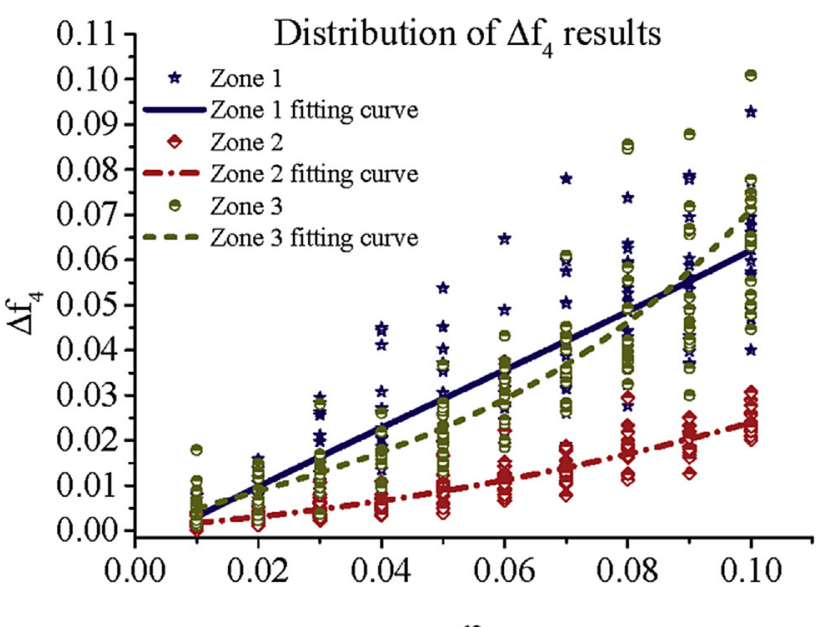

$\eta$

(d)

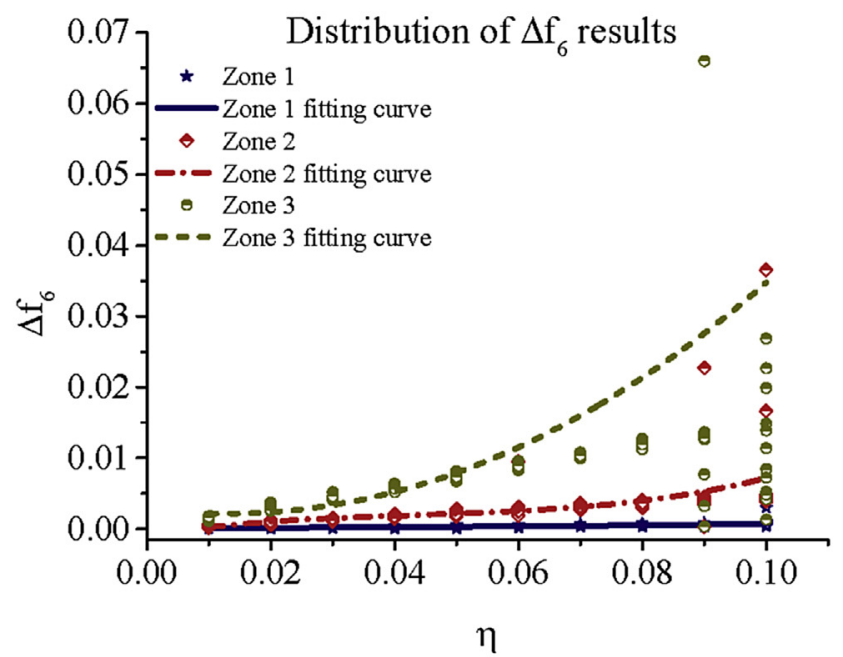

(f)

Fig. 9. $\Delta \mathrm{f}_{\mathrm{i}}$ results of the specimen in the case of CFFF. (a) 1 st mode. (b) 2 nd mode. (c) 3rd mode. (d) 4 th mode. (e) 5 th mode. (f) 6 th mode. 


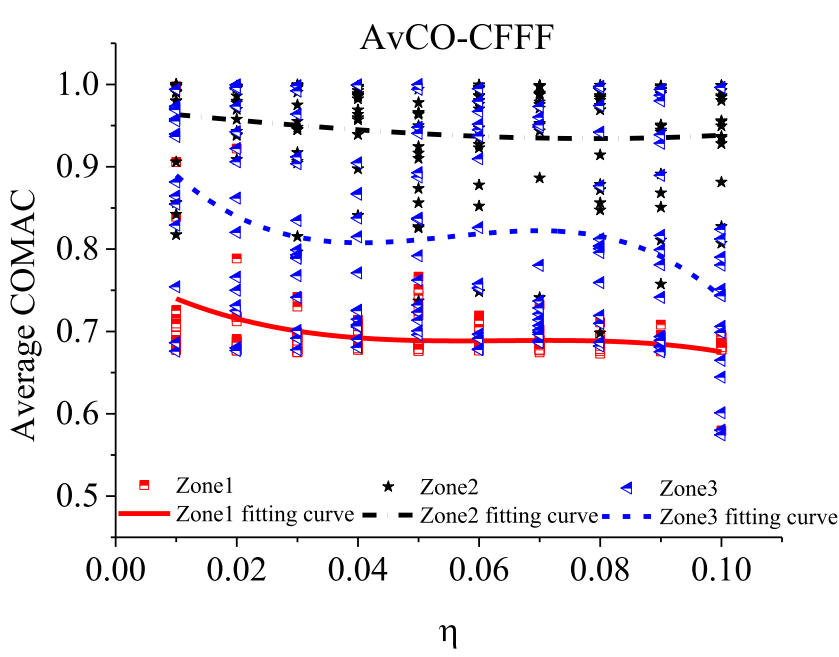

(a)

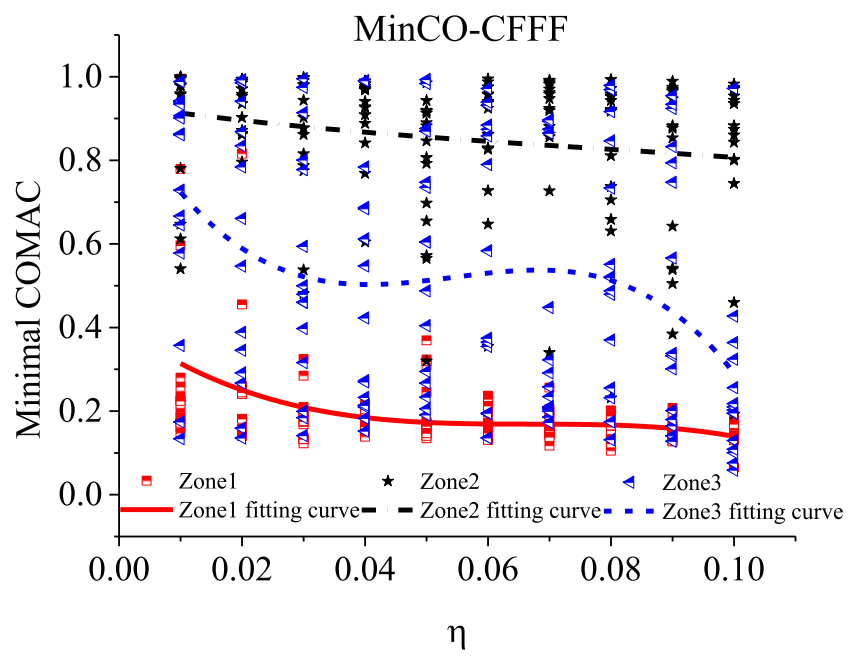

(b)

Fig. 10. Local evaluation parameters' results of the specimen in the case of CFFF. (a) AvCO. (b) MinCO.

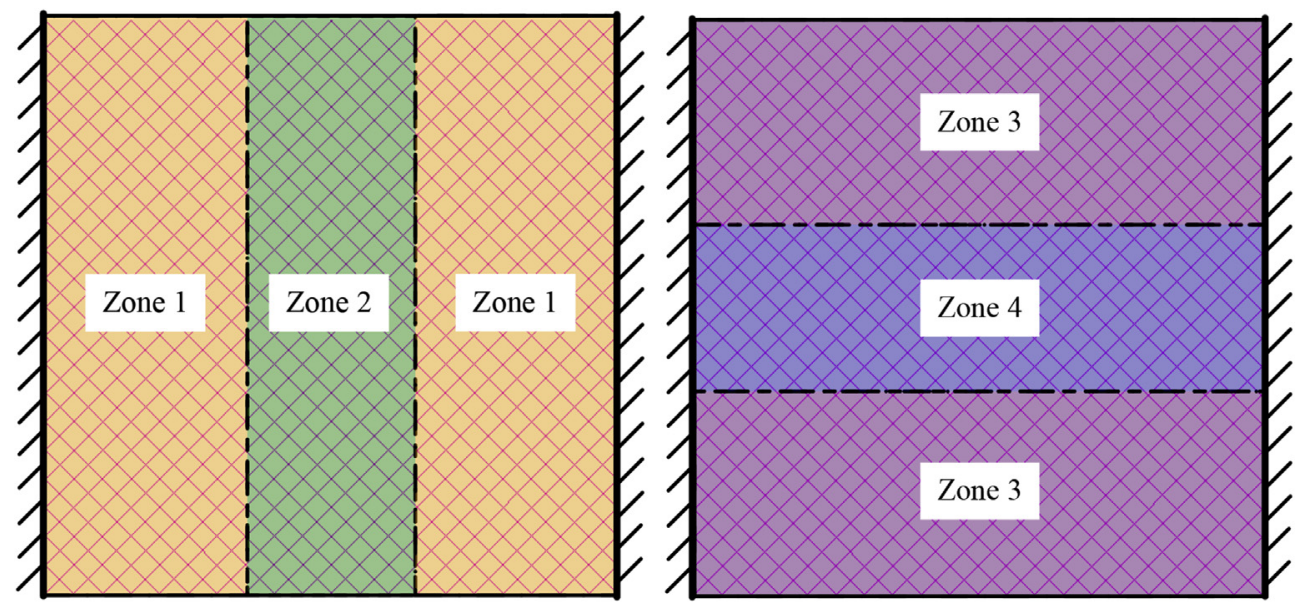

Fig. 11. Four zones of the specimen in the case of CCFF.

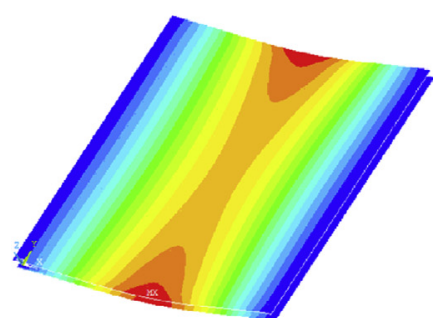

(a)

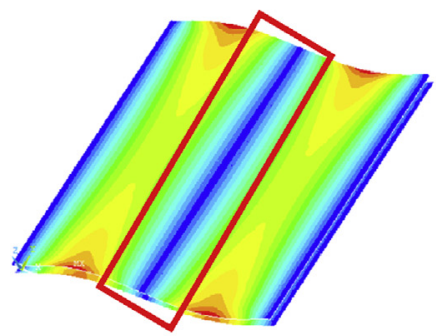

(d)

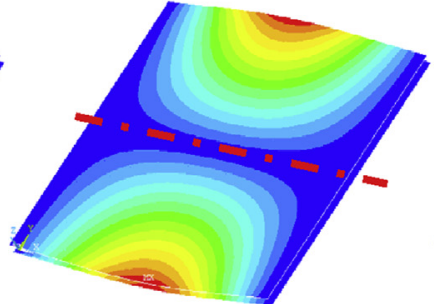

(b)

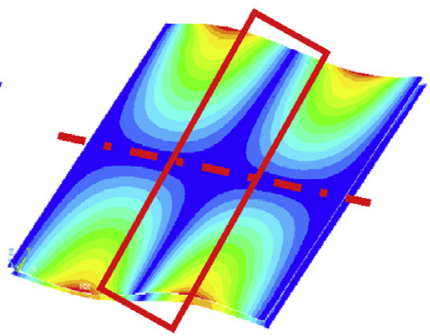

(e)

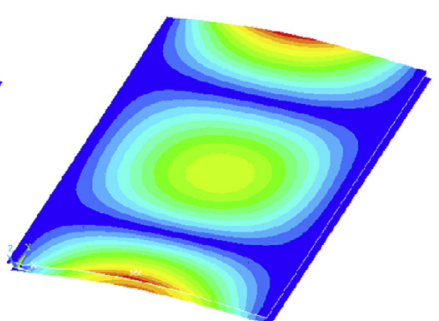

(c)

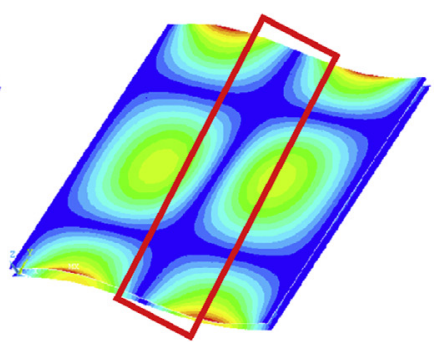

(f)

Fig. 12. First six modes in the case of CCFF. (a) 1st mode. (2) 2nd mode. (3) 3rd mode. (4) 4th mode. (5) 5th mode. (6) 6th mode. 


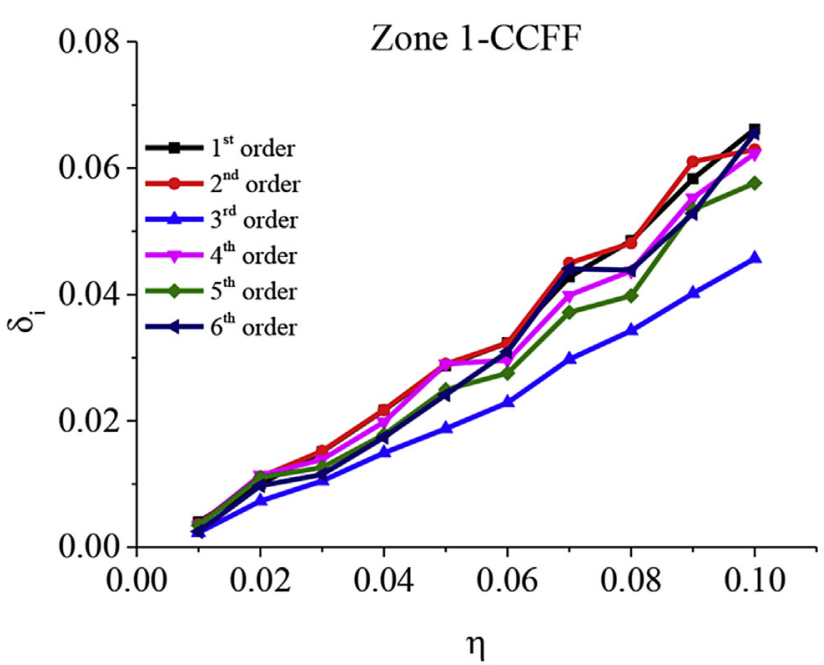

(a)

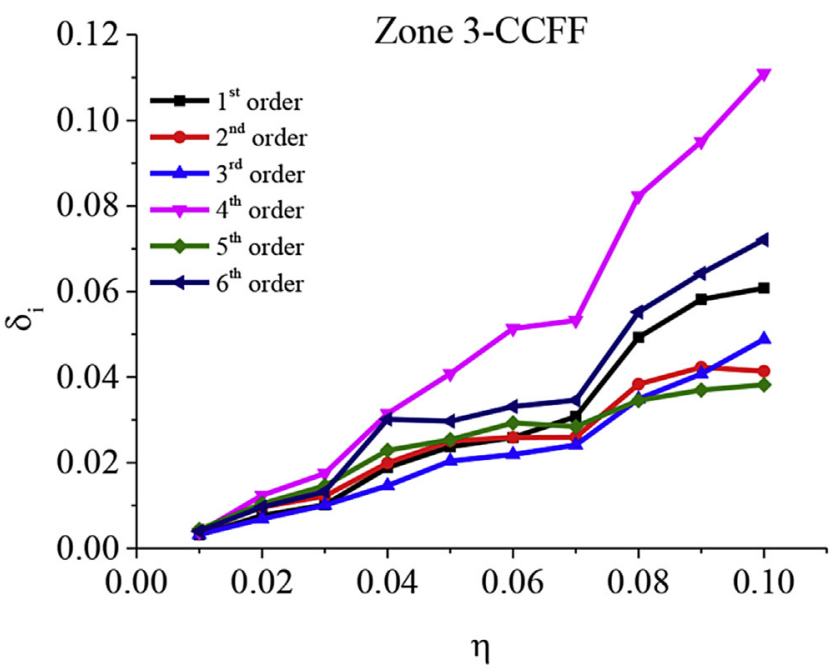

(c)

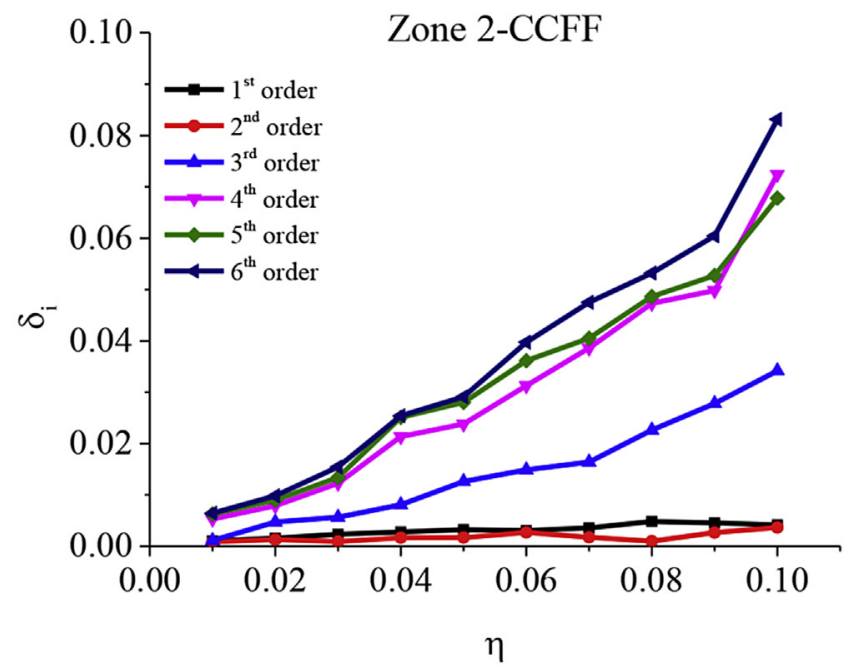

(b)

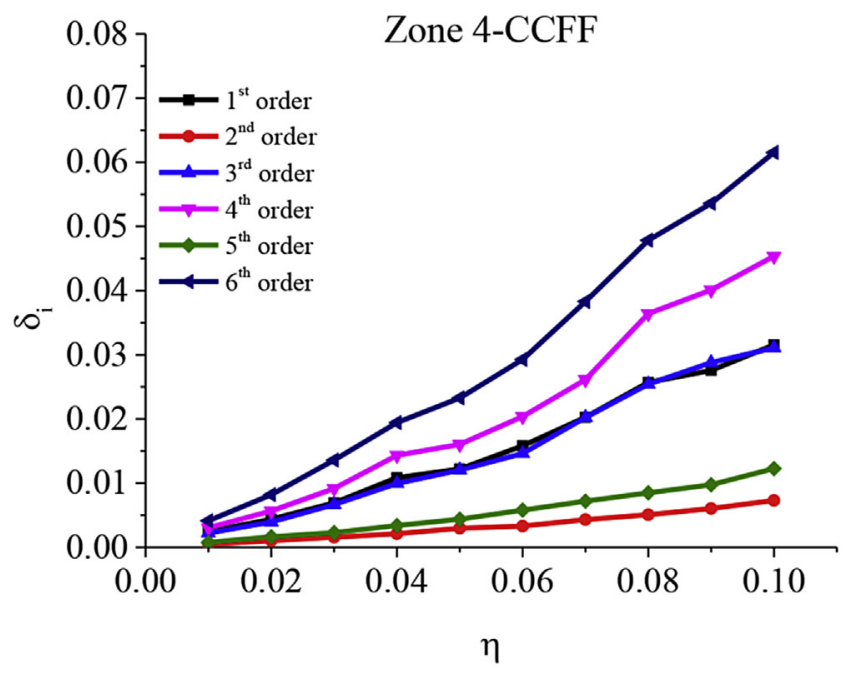

(d)

Fig. 13. $\delta_{i}$ results of the specimen in the case of CCFF. (a) Zone 1. (b) Zone 2. (c) Zone 3. (d) Zone 4 .

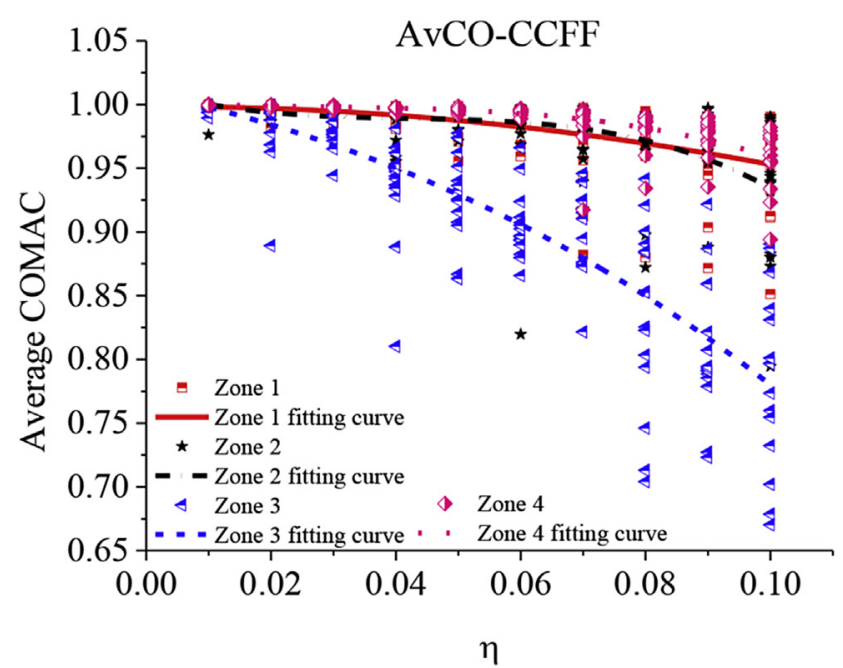

(a)

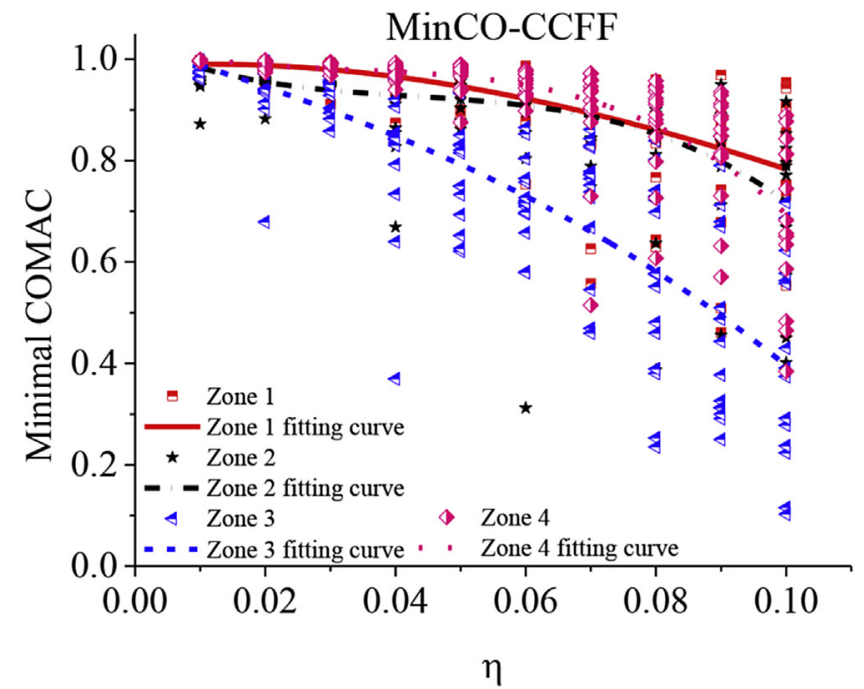

(b)

Fig. 14. Local evaluation parameters' results of the specimen in the case of CCFF. (a) AvCO. (b) MinCO. 
damages in zone 3 would be larger than damages in other zones, as blue fitting curves shown in Fig. 14 (a) and (b). Besides, maximal $\delta_{i}$ caused by damages in zone 3 is also larger than those caused by damages in other zones as shown in Fig. 13. It demonstrates variation tendencies of natural frequencies and mode shapes are in accordance.

In general, damages in the zone covering SPTCs' local vibration modes and maximal vibration amplitude would have greater influences on structural modes (natural frequencies and mode shapes). Effects of random damages on the two types of evaluation parameters, which evaluates natural frequencies and mode shapes respectively, usually agree well.

\subsubsection{Boundary condition CCCC}

The CCCC SPTC specimen is divided into three zones, as shown in Fig. 15. The first six mode shapes are shown in Fig. 16, and evaluation parameters' results of three zones are displayed in Fig. 17 and Fig. 18.

From Fig. 17, the maximal $\delta_{i}$ caused by damages in zone 1, 2 and

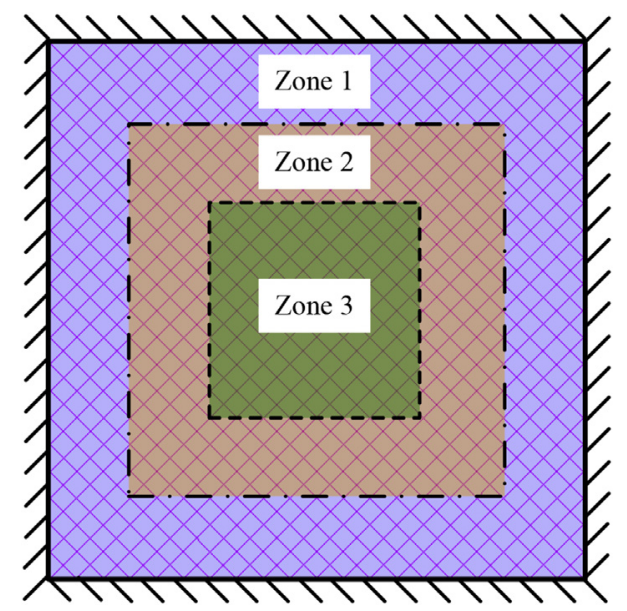

Fig. 15. Three zones of the specimen in the case of CCCC.
3 are about $10 \%, 8 \%$ and $20 \%$ respectively, i.e., variations of natural frequencies caused by damages in zone 3 are much larger than damages in zone 1 and 2. According to AvCO and MinCO results in Fig. 18, it is observed that the same trends of variations of mode shapes could be obtained, i.e., variation of mode shapes caused by damages in zone 3 is much larger than those caused by damages in zone 1 and 2 . As zone 3 is in the center of the specimen and random damages in the zone are more concentrated than damages in zone 1 and zone 2. Meanwhile, zone 3 covers the central axis region of 2 nd, 3rd, 4th, 5th and 6th modes, in which damages are easier to change structural stiffness as well as the dynamic behavior of SPTCs. And zone 3 also covers the maximal vibration amplitude of 1 st and 6th modes. Besides, according to Fig. 17, it is seen that the sensitivity of some order of mode to damages in different zone are quite different. To sufficiently analyze the sensitivity of dynamic performance to damages, distribution of damages and mode shapes should be supplied.

Results in the case of CCCC indicate that the effect of random damages on dynamic property is in proportional to the concentration degree of random damages in the same damage extent.

\section{Conclusions}

In the paper, the effect of random damages on dynamic behavior of SPTCs is investigated through finite element models in conjunction with stochastic number program, and three factors are considered, including damage extent, boundary condition and damage zone. Two sets of evaluation parameters are defined to analyze the influences of random damages on structural dynamic properties. Experiments were conducted to verify the proposed analysis technique. Based on the results, some conclusions could be obtained:

The effect of damages on structural vibration property is in proportional to the damage extent. At the same damage extent, the effect of damages is in proportional to the concentration degree of random damages.

At the same damage extent, the significance of damages on the dynamic property of SPTC typically increases in the order of CFFF, CCFF and CCCC. When the constraint of boundary condition

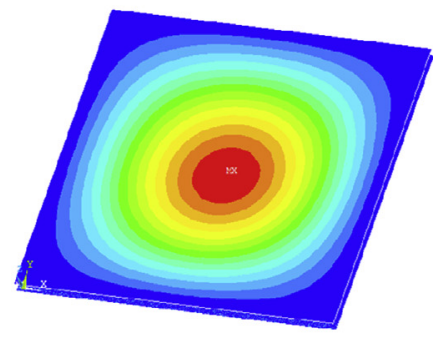

(a)

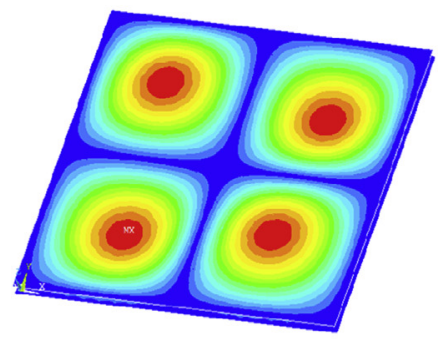

(d)

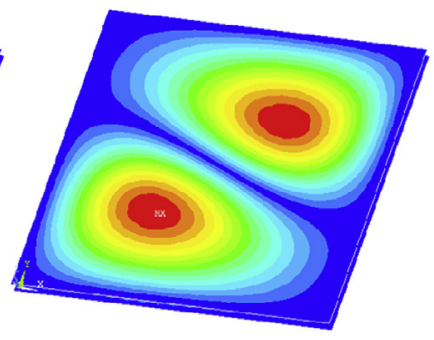

(b)

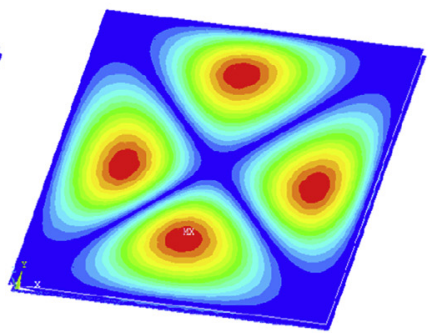

(e)

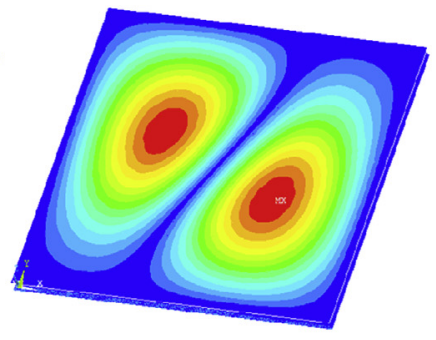

(c)

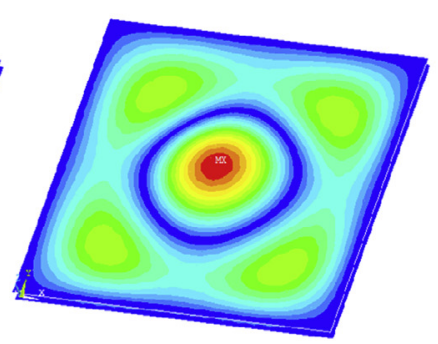

(f)

Fig. 16. First six modes in the case of CCCC. (a) 1st mode. (b) 2nd mode. (c) 3rd mode. (d) 4th mode. (e) 5th mode. (f) 6 th mode. 


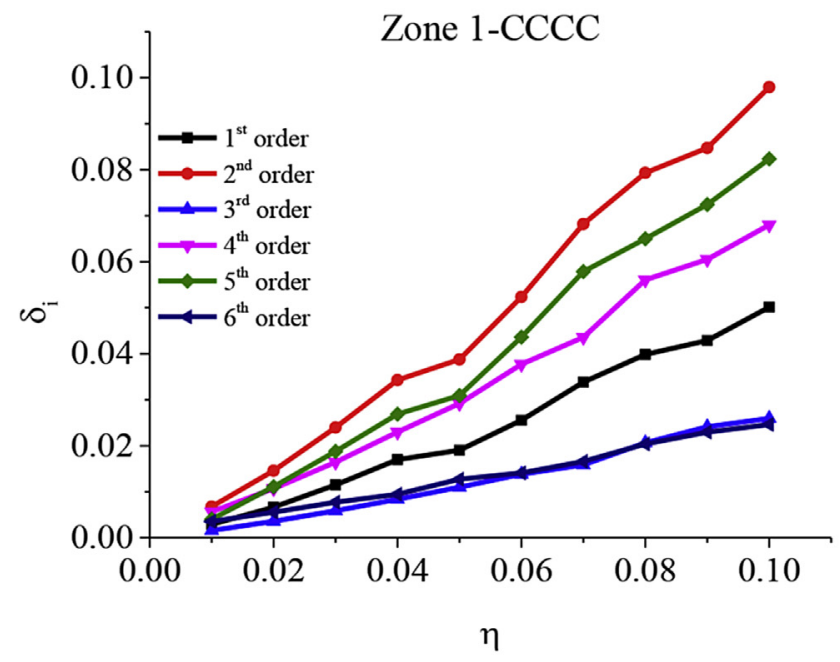

(a)

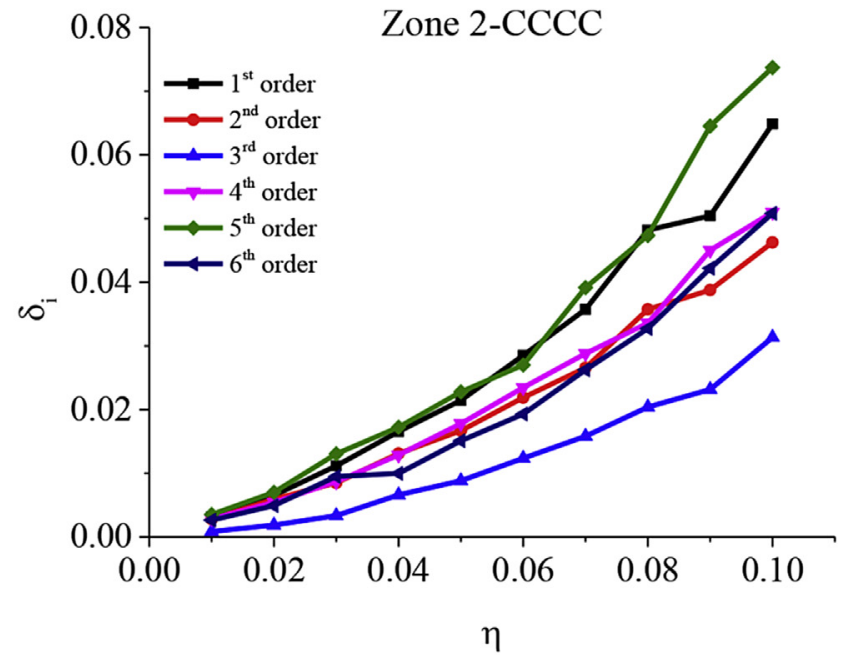

(b)

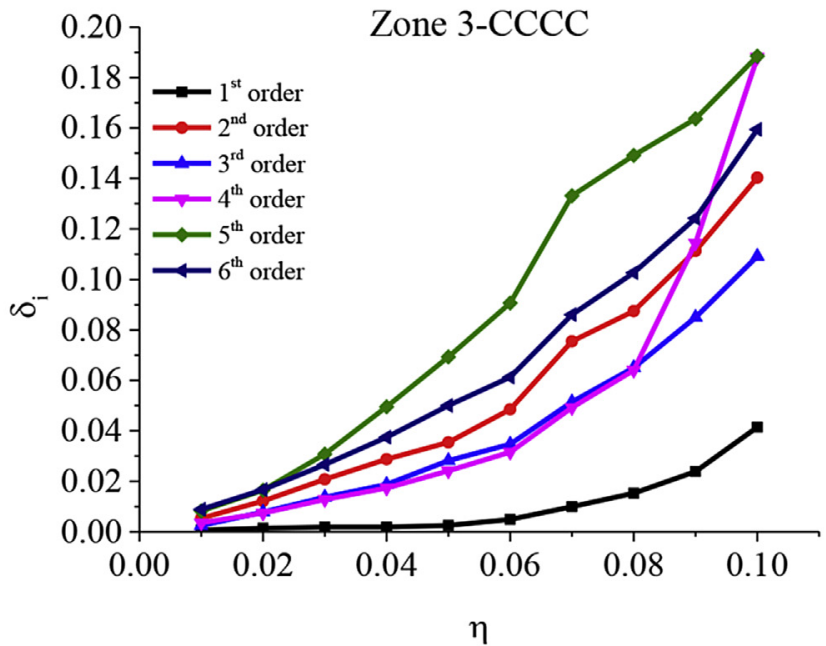

(c)

Fig. 17. $\delta_{\mathrm{i}}$ results of the specimen in the case of CCCC. (a) Zone 1. (b) Zone 2. (c) Zone 3.

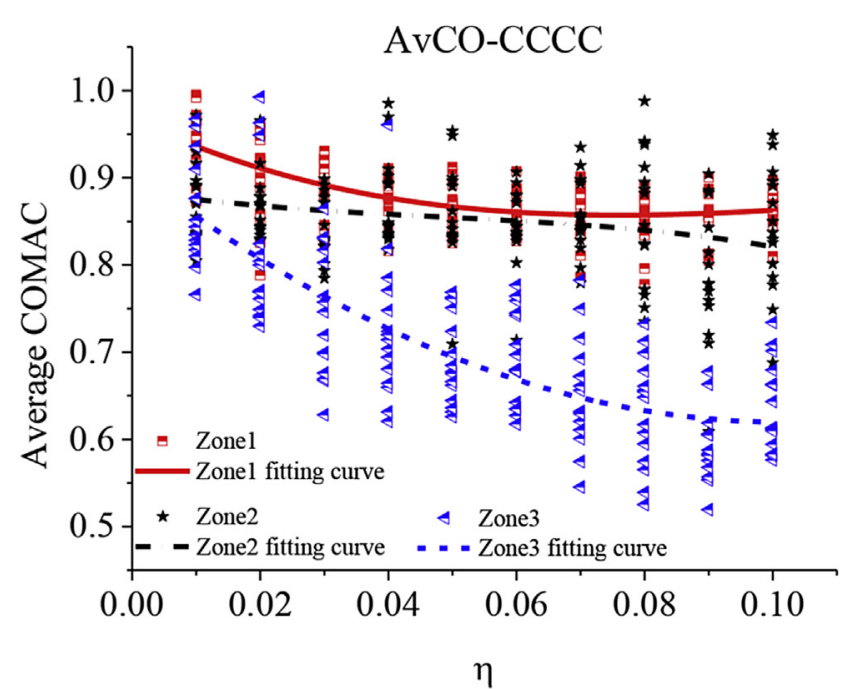

(a)

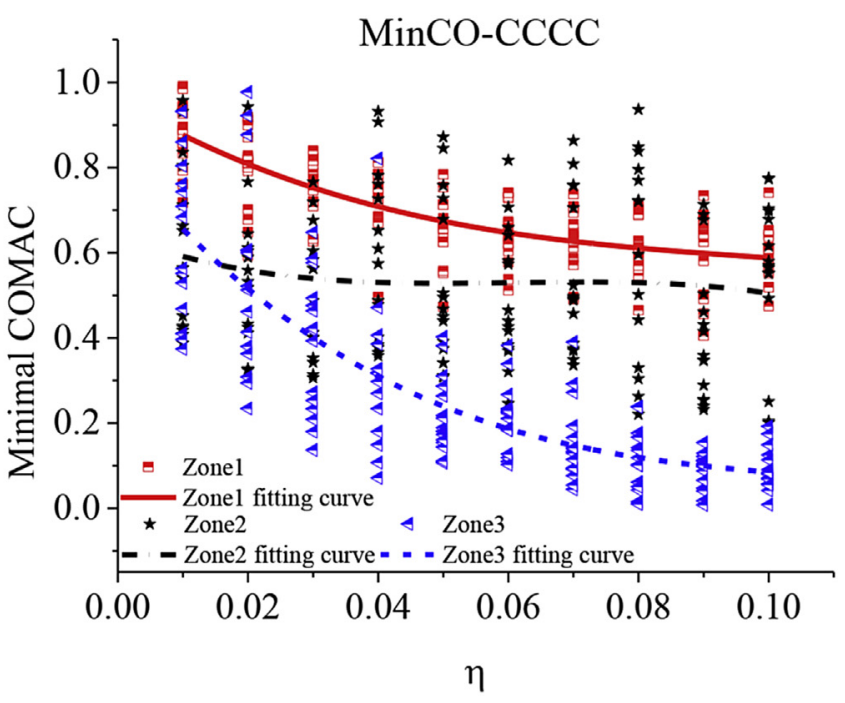

(b)

Fig. 18. Local evaluation parameters' results of the specimen in the case of CCFF. (a) AvCO. (b) MinCO. 
increases, vibration modes become complicated and detailed local vibration modes appear, and the damage sensitivity of complicated modes is higher than those of relatively simple modes.

Damages in the zone covering structural local vibration modes and maximal vibration amplitude would have greater influences on structural modes (natural frequencies and mode shapes) than damages in other zones. Effects of random damages on both natural frequencies and mode shapes are usually in accordance.

The influence of damage zones on the dynamic property of SPTCs should be considered by combining the boundary condition, mode shape and damage extent. The damage sensitivity of a mode is determined by the complex factors of damage extent, boundary condition, damage zone or distribution, mode shape and the concentration degree of damages.

\section{Acknowledgements}

This research is supported by the National Natural Science Foundation of China under grant Nos. 11472276, 11332011 and 11502268, and Defense Industrial Technology Development Program of China, No. JCKY2016130B009.

\section{References}

[1] Evans AG, Hutchinson JW, Fleck NA, Ashby MF, Wadley HNG. The topological design of multifunctional cellular metals. Prog Mater Sci 2001;46:309-27.

[2] Wang J, Lu TJ, Woodhouse J, Langley RS, Evans J. Sound transmission through lightweight double-leaf partitions: theoretical modeling. J Sound Vib 2005:286(4-5):817-47.

[3] Zumpano G, Meo M. Damage detection in an aircraft foam sandwich panel using nonlinear elastic wave spectroscopy. Comput Struct 2008;86:483-90.

[4] Panopoulou A, Loutas T, Roulias D, Fransen S, Kostopoulos V. Dynamic fiber Bragg gratings based health monitoring system of composite aerospace structures. Acta Astronaut 2011;69:445-57.

[5] He YZ, Tian GY, Pan MC, Chen DX. Non-destructive test of low-energy impact in CFRP laminates and interior defects in honeycomb sandwich using scanning pulsed eddy current. Compos Part B-Eng 2014;59:196-203.

[6] Jing L, Wang ZH, Zhao LM. An approximate theoretical analysis for clamped cylindrical sandwich shells with metallic foam cores subjected to impulsive loading. Compos Part B-Eng 2014;60:150-7.

[7] Liu JY, Zhu X, Zhou ZG, Wu LZ, Ma L. Effects of thermal exposure on mechanical behavior of carbon fiber composite pyramidal truss core sandwich panel. Compos Part B-Eng 2014;60:82-90.

[8] Hg A. Analysis and design of structural sandwich panels. Oxford: Pergamon Press; 1969.

[9] Chiras S, Mumm DR, Evans AG, Wicks N, Hutchinson JW, Dharmasena K, et al. The structural performance of near-optimized truss core panels. Int J Solids Struct 2002;39:4093-115.

[10] Wadley HNG, Fleck NA, Evans AG. Fabrication and structural performance of periodic cellular metal sandwich structures. Compos Sci Technol 2003;63: 2331-43.

[11] Yuan W, Wang X, Song HW, Huang CG. A theoretical analysis on the thermal buckling behavior of fully-clamped sandwich panels with truss cores. J Therm
Stress 2014;37:1433-48.

12] Yuan W, Song HW, Wang X, Huang CG. Experimental investigation on therma buckling behavior of fully-clamped truss-core sandwich panels. AIAA 2015;53(4):948-57.

[13] Russell B, Hilary BS. Imperfection sensitivity of pyramidal core sandwich structures. Int J Solids Struct 2007;44:4690-706.

[14] Evans AG, Hutchinson JW, Ashby MF. Multifunctionality of cellular meta systems. Prog Mater Sci 1998;43(3):171-221.

[15] Hu JS, Hwu C. Free vibration of delaminated composite sandwich beams. AIAA J 1995;33(10):1911-8.

[16] Kim HY, Hwang W. Effect of debonding on natural frequencies and frequency response functions of honeycomb sandwich beams. Compos Struct 2002;55 $51-62$.

[17] Sokolinsky VS, Bremen HF, Lesko JJ, Nutt SR. Higher-order free vibrations of sandwich beams with a locally damaged core. Int J Solids Struct 2004;41: 6529-47.

[18] Burlayenko VN, Sadowski T. Influence of skin/core debonding on free vibration behavior of foam and honeycomb cored sandwich plates. Int J Non-Linear Mech 2010;45(10):959-68.

[19] Baba BO, Thoppul S. An experimental investigation of free vibration response of curved sandwich beam with face/core debond. J Reinf Plast Compos 2010;29(12):3208-18.

[20] Buket OB, Srinivasa T, An experimental investigation of free vibration response of curved sandwich beam with face/core debond. J Reinf Plast Comp 2010;0(00):1-11.

[21] Lou J, Wu LZ, Ma L, Xiong J, Wang B. Effects of local damage on vibration characteristics of composite pyramidal truss core sandwich structure. Compos Part B 2014;62:73-87.

[22] Yam LH, Yan YJ, Jiang JS. Vibration-based damage detection for composite structures using wavelet transform and neural network identification. Compos Struct 2003;60:403-12.

[23] Hu HW, Wang BT, Lee CH, Su JS. Damage detection of surface cracks in composite laminates using modal analysis and strain energy method. Compos Struct 2006;74:399-405.

[24] Kumar M, Shenoi RA, Cox SJ. Experimental validation of modal strain energies based damage identification method for a composite sandwich beam. Compos Sci Technol 2009;69:1635-43.

[25] Tian SX, Chen ZM, Chen LL, Zhang ZL. Numerical analyses on influence of damage configuration on vibration parameters for lattice sandwich plate. Int J Appl Electrom 2010;33:1565-72.

[26] Fan W, Qiao PZ. Vibration-based damage identification methods: a review and comparative study. Struct Health Monit 2011;10:83-111.

[27] Zhu KG, Chen MJ, Lu QH, Wang B, Fang DN. Debonding detection of honeycomb sandwich structures using frequency response functions. I Sound Vib 2014;333:5299-311.

[28] Andrzej K. Vibration-based spatial damage identification in honeycomb-core sandwich composite structures using wavelet analysis. Compos Struc 2014;118:385-91.

[29] Li B, Li Z, Zhou J, Ye L, Li E. Damage localization in composite lattice truss core sandwich structures based on vibration characteristics. Compos Struct 2015;126:34-51.

[30] Wallach JC, Gibson LJ. Defect sensitivity of a 3D truss material. Scr Mater 2001;45:639-44.

[31] Lieven NAJ, Ewins DJ. Spatial correlation of mode shapes, the coordinate modal assurance criterion (COMAC). Proceedings of the 6th international modal analysis conference. 1988. pp. 690-695.

[32] Carne TG, Dohrmann CR. A modal test design strategy for model correlation. In: Proceedings of the $13^{\text {th }}$ international modal analysis conference. Nashcille; 1995. 